\title{
Determining the Role of Project Management Office in the Success of Project-Based Organizations
}

\author{
Sarmad Kiania \\ Vahidreza Yousefi ${ }^{b}$ \\ Shahram Nouri*c \\ Amir Mohammad Khadivid \\ Ehsan Mehrabanfare \\ a.PhD Candidate of Construction and Project Management, University of Tehran, Tehran, Iran; Email: sarmadkiani@ut.ac.ir \\ b. PhD Candidate of Construction and Project Management, University of Tehran, Tehran, Iran; Email: vr.yousefi@ut.ac.ir \\ $c^{*}$ MSc in Construction and Project Management, University of Tehran, Tehran, Iran \\ d. MBA. Faculty of Management, Science \& Technology, Amirkabir University of Technology, Tehran, Iran \\ e. Young Researchers and Elites Club, North Tehran Branch, Islamic Azad University, Tehran, Iran \\ *Corresponding Author Email: e.mehrabanfar@gmail.com
}

Doi:10.5901/mjss.2015.v6n6s2p325

Abstract

The present research investigates the role of project management office in project efficiency and thus its success. The statistical population used in this work includes construction corporations active in the Iran construction industry and familiar with the concept of project management office. In such organizations, existence of the project management office and the success of their projects is firstly assessed and the role of the project management office in success of the organization's project as well as comparison of them with each other is then studied. For this purpose, a quantitative research methodology in the form of survey, along with designing a questionnaire with the help of 5-point Likert scale have been used. The results obtained indicate the existence of a highly strong linear relationship between the existence of project management office and the success of project. The results also show that the more highlighted the features of this office such as methods and standards for project management, project history archive, cooperation between employees/human resources office, project management educating and project administrative support, the more the success aspect of the project will be. Finally, the mentioned inferential statistics and qualitative features lead to generation of practical guidelines for organizations which have or are seeking to establish project management office.

Keywords: Project management office (PMO); success of project; project-based organizations

\section{Introduction}

A lot of construction projects fail due to exceeding time and cost, making organizations incur great expense, in addition to wasting national resources. On the other hand, since there is not any certain definition for success and failure, exceeding time and determined budget is considered as failure in all projects, while exceeding time and cost may not be sufficient criteria for assessment of success and failure of projects.

With respect to the above, organizations have become oriented towards project management science in order to deal with their project's exceeding of determined time and cost and achieve standard criterion for assessment of success and failure of a project. So, project management science was established so as to realize project objectives.

Considering the growth of project management and its processes, it seemed necessary to create an organizational unit responsible for centralizing and coordinating management of the projects underway. So, the idea of establishing the project management office came up in order to reach this purpose and then reach the success of the project. But the question "Do cost spending for project management and establishing project management office have any impact on the success of a project?" has brought up a question for managers.

Although the history of project management office returns to the defense industries and construction in the United States between the years 1950 and 1960, it has been brought up over the recent decade. So, it seems necessary to 
conduct studies on the current role of PMO, along with the functions considered by project-based organizations.

The specific purposes of this research are to investigate the role of PMO in success of the project and to make some recommendations in order to implement the PMO successfully. In addition, the subsidiary questions of the present work are "which services and duties of the PMO do have the maximum impact on the project success?", "Does the PMO make the organization propel into the learner organization?", and "In which of the triple criteria for success does the PMO have the most impact?"

\section{Research Literature Review}

\subsection{Project Management Office (PMO)}

It is impossible to present a comprehensive definition of PMO as a PMO working for an organization is created based on that organization's existing demands, culture, and efforts (Evaristo, 2006).

There are, however, some definitions of PMO within the literature of project management as follows:

- $\quad \mathrm{PMO}$ is an organizational unit responsible for centralizing and coordinating the management of the undertaken projects. It is also called "plan management office", "project office", or "plan office" (PMBOK, 2013).

- PMO is a concentrated integrating resource and a knowledge repository which can be used to do the information process more effectively and more efficiently in project management [1].

- PMO (Centre of Excellence or Center of Expertise) is an independent organizational institute established to assist project managers, teams, and several managerial levels in strategic cases and functional independent institutes in implementing project management principles, patterns, approaches, tools and technologies (Ward, 2000).

- It is worth noting that PMO is a permanent section of an organization, not a temporary job or an out-sourced activity, and is designed to improve the consultation process for the success of project management at an organizational level.

This pattern is often known as Project Management Office (PMO) or Center of Expertise. It should be noted that in project management research literature, PMO is known as Plan Office, Portfolio Office, etc. In the present work, however, only the role of this office in the success of the project has been investigated. PMO is responsible for management supervisory of projects, plans, or a combination of them. Projects supported or administered by the PMO cannot be transferred to another or managed jointly although some PMOs get coordinated with each other and manage related projects. In many organizations, such projects, which are actually joint projects or are somehow related to each other, the $\mathrm{PMO}$ is focused on coordinated planning, prioritization and implementation of projects and sub-projects which are tied to the whole organization's business purposes or to the main clients. PMOs may hierarchal provide support for project management, ranging from educating, software, standardization policies, and procedures to responsibility and direct management in order to reach the project purposes.

A PMO can be a representative of a stakeholder or a key decision-maker during the initiation phase of any project so as to make some recommendations or stop some projects for maintaining its business goals. Furthermore, a PMO is able to choose, manage, and transfer joint personnel of projects or, if needed, transfer project personnel (PMBOK, 2013).

If the PMO is implemented properly, it would be possible to prevent the highly-challenging outcomes of project management by capturing and transferring of knowledge, maximizing teams' cooperation potential, and adjusting demands for technologies.

The main essence and distribution of these offices vary depending on the PMO level and its pattern.

PMOs are often responsible for conducting projects undertaken by organizations in order to reach that organization's strategic intends.

Most of the PMOs committed to work for organizations depend on that organization's budget and resources.

PMOs are responsible for the development of standards and methodologies of project management as well as the development of the organization's capability based on the pattern of these methodologies. Based on these goals, the PMO is able to integrate any of the following combinations. (Bates, 1998), (Deguzman, 1999), (Frame, 1998), (Frame, 1998),( Jr., W. G, 1999), (Knutson, 1995), (Koppelman, 1998),( Levine, 1996), (Vandersluis, 1998), (Noori, 2009)

- Knowledge management: Making use of knowledge in the best way using best patterns in projects managed by the organization, and learning lessons from the projects conducted in the organizations. The knowledge is used by the other parts of the organization including engineering, research and development, etc., making the organization's products and services improved.

- Projects procedures and processes: Recognition of the organization's project management methodology and the criteria used to evaluate the failure or success of the projects, which leads the organization to gain ability 
to recognize and re-use the project management framework in order to conduct the tasks done within the organization.

- Providing education for project teams: Management of project mangers' educational requirement in order to persuade them to accept the fact that mangers are the best and most effective factors for dealing with project complexities, managing customers' expectations and recruiting the project team members.

- Project resources: Managing the personnel recruitment process, equipment, office space, and the other resources so as to make the optimized use of human resources.

- Management of project portfolio: Managing and coordinating multiple projects which are similarly and continuously under progress within the organization. This means observing the characteristics and special risks of the projects in progress, and comparing them with those completed in the past, so to make good planning.

- Financial management of the project: It is believed that a project depends on the budget, and this fact affects the total market value of the organization.

\section{Project Success}

The term "Success" in project management science is considered in two dimensions; measurement indexes, and key factors. The concept of "Critical Success Factors" was first brought up by Rabin and Siling, and was then used by Rockert for the first time as a term (Terry \& Davies, 2002), (Toor \& Ogunlana, 2008). According to the definition of critical success factors, they are factors, relying which it is possible to increase the chance to obtain successful results from plans or projects. These are measurable factors which mostly lead to success when appeared in the plan or project environment.

Success measurement criteria, on the other hand, are those criteria by which it is possible to judge whether the project or plan has been successful. In other words, it would be possible to draw a conclusion on the success of a project or plan by specifying such criteria and determining how to measure them. Creating a connection between critical success factors and success criteria can be brought up as a model of excellence for success. Care has to be taken to the important difference between the critical success factors and success criteria. Belassi et al. stated that a suitable research on project success should have the following characteristics (Belassi \& Tukel, 1996), (Balck, 1990):

1) Distinction between success factors and success criteria

2) Distinction between success factors inside the gamut of project manager's control and those outside it

Project success is different from project management success. Project success may be assessed through obtaining the overall purposes of the project, while project management success is measured by traditional performance tools in terms of time, cost, and quality (Terry \& Davies, 2002), (Ahadzie, 2007), (Baccarini, 1993).

In most of the project management literature resources, project success is measured through obtaining success criteria including area, time, cost, and quality. PMBOK (Project Management Body of Knowledge) considers the project success measurement as following (PMBOK, 2013), (The standard for program management, PMI, 2013):

Success is measured by output, project quality, scheduling, compliance with budget and the level of customer satisfaction.

During another research, Pinto defines project success using cost, schedule, and performance, as shown in the table 1. In addition to the general criteria for project success (cost, schedule, and performance), the definition includes technical validity, organizational validity, and organizational effectiveness, which are considered as a matter in estimation of project success when applying the contribution of the employer's satisfaction (Pinto, 1986), (Bayers, 1989), (Bruno, 2000), (Kerzner, 1992).

Table 1. Project success

\begin{tabular}{ll}
$\begin{array}{l}\text { Cost } \\
\text { Schedule } \\
\text { Performance including: }\end{array}$ & $\begin{array}{l}\text { Necessity of achieving or getting close to the budget allocated to the project } \\
\text { Importance of obtaining the specified timeframe for the project }\end{array}$ \\
$\begin{array}{l}\text { Technical validity } \\
\text { Organizational validity }\end{array}$ & $\begin{array}{l}\text { Technical validity means if the project is completely technical, and meeting the minimum criteria for } \\
\text { technical performance. }\end{array}$ \\
\hline $\begin{array}{l}\text { Organizational validity of project acceptance by the project team members and employers who finally } \\
\text { receive the results of the project. }\end{array}$ \\
Organizational effectiveness $\begin{array}{l}\text { Organizational effectiveness is considered as an advancement for the organization, which is obtained } \\
\text { through more effective decision-making or the employer's performance }\end{array}$
\end{tabular}


Furthermore it is important to consider the relation between project success and the success of other initiatives including programs or portfolios. "Critical success factors for projects are not necessarily the same as critical success factors for program but they may play a considerable role in program success. In other words, if all the projects of one program are successfully performed, it will not be guaranteed to have successful program." (Kiani et al., 2014)

Research literature review leads to identification of the following classification as for the PMO's duties and services:

1. Development and maintenance of methods and standards of project management

2. Development and maintenance of project history archive

3. Project's administrative tasks commitment

4. Assisting in recruiting and deploying the project team

5. Providing project management educating

6. Advising and guiding project mangers

7. Management of project portfolio

Reviewing project success literature, the following criteria were identified as to be project success criteria in the present research:

1. Achieving project results (including schedule, cost, performance, etc.)

2. Project personnel's satisfaction

3. Project stakeholders' satisfaction

4. Learning

\section{Research Methodology}

First an extensive library research was conducted so as to get familiar with the subject literature including internet books and papers existing on accredited websites. It is worth noting that considering the limitation of conducting research in the country and organizations' lack of familiarity with the concepts of project management literature, 30 organizations and corporation active in Iran construction industry, who were thoroughly familiar with project management literature, PMO, and success criteria, were selected as the statistical population of the research in order to maintain the normality of the results. Researches and theses related to the field of the present work as well as researches conducted by accredited project management organizations such as PMI were used to prepare the research questionnaires. After the beginning of library researches and briefly field study on the organizations in question, the research questionnaire was prepared using a five-point Likert scale. In this questionnaire, existence of PMO within the organization as well as its role in the success of the projects already completed and superintended by the PMO were identified.

In order for the participants to better understand the questionnaire and be careful in responding, it was filled with the presence of the researcher. The questionnaire design aimed at investigating the amount of the role of PMO in projects success, although the functions of this office may be performed under other names or titles in these organizations.

At the end, some recommendations were made so as to implement the PMO with respect to the organization's culture and some suitable strategies offered in order to improve the current circumstances.

It is worth noting that in this research, survey method was used to answer the main question and correlation methodology to investigate the relationship between independent and dependent variables. The present work is quantitative in terms of data gathering and practical in terms of purpose.

Since the research was conducted in a quantitative manner, some assumptions related to the main question of the research were created, which will be confirmed or rejected in the following.

Null Hypothesis (H0): existence of the PMO has no linear relationship with project success.

$$
\left\{\begin{array}{l}
H_{0}: \rho=0 \\
H_{a}: \rho \neq 0
\end{array}\right.
$$

Alternative Hypothesis $\left(\mathrm{H}_{\mathrm{a}}\right)$ : existence of the PMO has linear relationship with project success.

Also, the assumptions related to the secondary questions of the research are as follows:

- There is a linear relationship between the methods and standards of project management and project success. 1=Ha-PMO

- There is a linear relationship between the research history archive and project success. 2=Ha-PMO

- There is a linear relationship between the project's administrative tasks commitment and project success. 3=Ha-PMO 
- $\quad$ There is a linear relationship between assisting in recruitment and using the project team and project success. 4=Ha-PMO

- $\quad$ There is a linear relationship between project management educating and project success. 5=Ha-PMO

- $\quad$ There is a linear relationship between advising and guiding project managers and project success. 6=Ha-PMO

- $\quad$ There is a linear relationship between management of project portfolio and project success. 7=Ha-PMO

\section{Research Findings}

T-test was used in order to test the main assumption of the research. For this purpose, first the test statistic was calculated using the following formula:

$$
r=\frac{n \sum_{i=1}^{n} X_{i} Y_{i}-\sum_{i=1}^{n} X_{i} \sum_{i=1}^{n} Y_{i}}{\sqrt{n \sum_{i=1}^{n} X_{i}^{2}-\left(\sum_{i=1}^{n} X_{i}\right)^{2}} \sqrt{n \sum_{i=1}^{n} Y_{i}^{2}-\left(\sum_{i=1}^{n} Y_{i}\right)^{2}}}
$$

Where

$\mathrm{R}$ is test statistic, $\mathrm{X}_{i}$ 's are the scores gained by PMO in the questionnaire, and $Y_{i}$ 's are the scores gained by success in the questionnaire.

After performing the calculation, the assumption $\mathrm{H}_{0}$ is rejected since the test statistic value is within the critical region $(\mathrm{r}=0.687)$.

P-Value $=0.014<\alpha=0.05$

So with the confidence level of 95\%, the assumption that existence of the PMO has a linear relationship with project success is confirmed.

Since the two variables have been measured at the Likert distance scale, Pearson correlation coefficient was used to determine the amount of correlation between "PMO's services and duties" and "project success". In addition to calculating the Pearson correlation coefficient between "PMO's services and duties" and "project success", it was also calculated between "existence of PMO" and "project results", "partners' satisfaction", and "learning".

Results obtained from this analysis are presented in tables 2 and 3.

Table 2. Pearson correlation coefficient between existence of PMO and success criteria

$\begin{array}{lcccc}\text { Variable } & \text { Project results } & \text { Personnel's satisfaction } & \text { Parties' satisfaction } & \text { Learning } \\ \text { Pearson correlation coefficient with PMO } & 0.75 & 0.468 & 0.558 & 0.788 \\ \text { P-Value } & 0.005 & 0.125 & 0.059 & 0.002\end{array}$

Since the correlation analysis is carried out assuming confidence level of $95 \%$, all of the success criteria in the analysis presented in table 2 , whose P-value is less than 0.05 , have a correlation with existence of the PMO, as shown in figure 1.

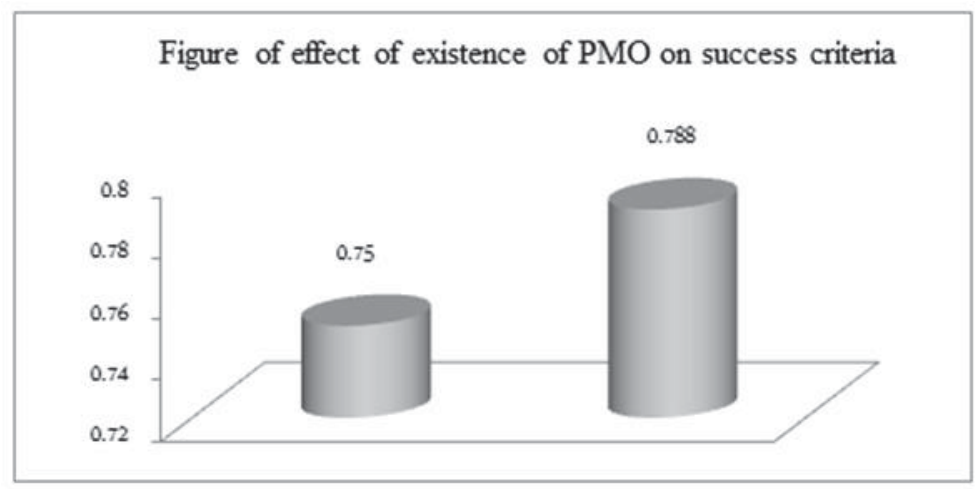

Figure 1. Effect of existence of PMO on success criteria 
Table 3. Pearson correlation coefficient between PMO's services and duties and project success

$\begin{array}{lcc}\text { PMO's services and duties } & \text { Pearson correlation coefficient } & \text { P-Value } \\ \text { Methods and standards of project management } & 0.699 & 0.011 \\ \text { Project history archive } & 0.494 & 0.104 \\ \text { Project's administrative duties commitment } & 0.149 & 0.644 \\ \text { Assisting in recruiting and deploying the project team } & 0.462 & 0.013 \\ \text { Education } & 0.425 & 0.0168 \\ \text { Advising and guiding } & 0.165 & 0.050 \\ \text { Management of project portfolio } & 0.608 & 0.136\end{array}$

Like the table 1 analysis, all of the services and duties in the analysis presented in table 2, whose P-value is less than 0.05 , have a correlation with project success, as shown in figure 2 .

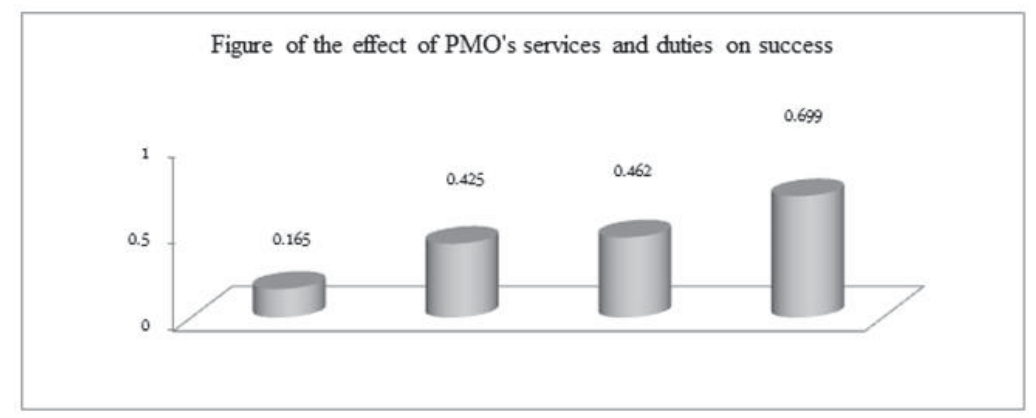

Figure 2. Effect of PMO's services and duties on project success

Since the linear relationship between existence of PMO and project success was confirmed by t-test, the following linear regression equation the two variables was obtained in order to predict the dependent variable (project success) by an independent variable (existence of PMO).

Success Score $=0.739+0.923$ PMO Score

$\begin{array}{lcccc}\text { Predictor } & \text { Coefficient } & \text { SE Coefficient } & \text { T } & \text { P } \\ \text { Constant } & 0.7388 & 0.9932 & 0.74 & 0.474 \\ \text { PMO Score } & 0.9226 & 0.3089 & 2.99 & 0.014 \\ \text { S }=0.493753 & \text { R-Sq }=47.1 \% & & \text { R-Sq(adj) }=41.9 \%\end{array}$

As the confidence level of $95 \%$ has been used in this work, it is considered to be used for analyzing the regression equation as well. In all cases where the P-value is less than 0.05 , the constant coefficient value as well as the PMO coefficient is accepted, otherwise zero is considered instead.

Since the P-value, the regression equation constant (constant $=0.474$ ) is larger than 0.05 , the value of this constant has been considered to be zero.

As for the PMO score, since the P-value (0.014) is less than 0.05 , the PMO coefficient $(0.923)$ is accepted.

So, considering the above analysis and the value of the adjusted determination coefficient (R-Sq(adj)), the equation is true for $42 \%$ of the cases.

\section{Analysis of Findings}

The correlation coefficient was calculated between "existence of PMO" and "project success" and Pearson correlation coefficient between "PMO's services and duties", and "project results", personnel's satisfaction", "partners' satisfaction", and "learning" with the confidence level of 95\%, as shown in figures 1 and 2.

As shown in figure 1, existence of PMO in the statistical samples of the research has the most relationship with only two success criteria with the confidence level of $95 \%$, as follows: 
1) Learning

2) Project results

This is because of the fact that in the organizations under study as well as in all of Iranian project-based organizations, organizations are looking for project results and learning ignoring PMO's other services and duties which play an important role in gaining contract parties' and project personnel's satisfaction. Their neglect causes success score in projects to lower, waste of human resource, and failure to achieve the parties' strategic goals. Implementation of projects in Iranian project-based organizations is focused only on schedule, cost, and quality. Of course, achieving project results (schedule, cost, and quality) has no standard definition in Iranian project-based organizations, and achieving project results just means to complete the project.

As for learning, only the implicit knowledge obtained from projects is used as action criterion for the organizations, which moves out of the organization due to the replacement of human resources and the passage of time.

So, it seems necessary to introduce a series of suitable strategies and joint literature in the construction industry in order to prevent waste of financial and human resources in projects.

Also as shown in figure 2, only four duties of PMO have the most relationship with project success in the present research, which are as following:

1) Methods and standards of project management

2) Assisting in recruiting and deploying the project team

3) Educating

4) Advising and guiding

The two other duties and services of PMO which are:

1) Project history archive

2) Project's administrative duties commitment

Do not have a correlation relationship with project success at the confidence of $95 \%$ in the samples under study.

\section{Summary and Conclusion}

Although organizations are generally about to gain success in terms of project results, those organizations, which seek permanent and sustainable growth, look for success in terms of another dimension that is learning.

Although PMOs may have no remarkable short-term effect on project results, the impact they have on learning will have long-term effect on project results, and stakeholders' and personnel's satisfaction.

In organizations, which seek permanent and sustainable growth, existence of PMO causes them to grow and become successful, as similar to a normal clock, as shown in figure 3. First, there are insignificant results, but as time goes by, it increases by an accelerating trend.

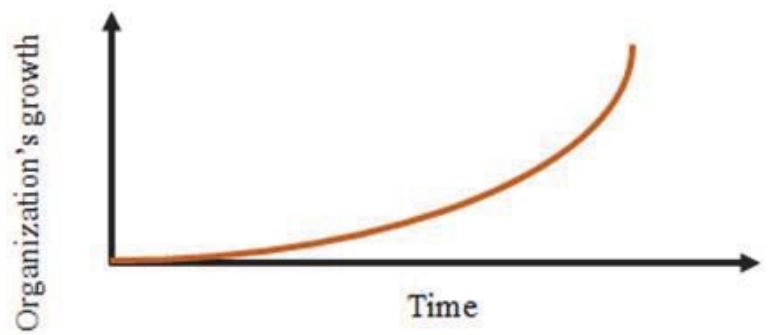

Figure 3. Growth of normal clock

In contrast, senior managers expect PMO to be the cause of organization's growth and success as similar to an artificial clock, as shown in figure 4 . It means the curve should have a constant velocity. 


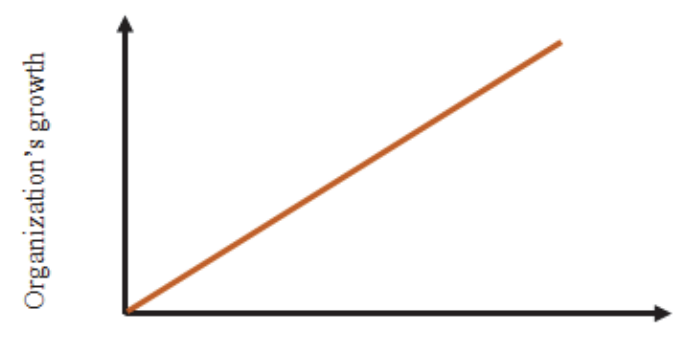

Time

Figure 4. Growth of artificial clock

With respect to the analyses and the recommendations resulted from them, it can be concluded that organizations should take the following steps respectively in order to implement the PMO:

1) Teaching the scope of project management knowledge

2) Implementing the PMO - support

3) Implementing the $\mathrm{PMO}$ - information manager

4) Implementing the $\mathrm{PMO}$ - knowledge manager

5) Implementing the PMO - Educator

Analyzing the correlation results, it is inferred that in the organizations under study, lack of suitable familiarity with PMO's services and duties causes lack of correlation between some of the PMO's services and duties and project success.

So, the first step in the implementation of the PMO in project-based organizations is to make familiarity with PMO's services and duties.

As the last point, it is really important to be patient while implementing the PMO, and the main purpose of the deployment should be learning. And it is necessary to make sure that learning will have direct and indirect effects on the project results and satisfaction.

\section{References}

Ahadzie D.K. and Proverbs D.G. and Olomolaiye P.O., Critical success Criteria for mass house building projects in developing countries, (2007).

Baccarini D., The logical framework method for defining project success, Project Management Journal, (1993), 30(4), 25-32.

Balck, H. "Project as a Form of Change, Handbook of Management by Projects, eD. Roland Gareis, MANZsche Verlages, Vienna, (1990), pages 22-28.

Bates, W. S. Improving Project Management: Better Project Management Begins with A Project Management Office, Industerial Engineering,v30n10, (1998), page42.

Bayers, L. U.S. Pharmaceutical Industry: A Standard for Success, Project Management Journal, v20n3, (1989), page 11.

Belassi, W and Tukel, QI, A new framework for determining critical succes/failure factors in Projects, International Journal of Project Management, (1996), 14(3), 141-51.

Bruno Urli, D. U. Project Management in North America, Stability of the Concepts, Project Management Journal, v31n3, (2000), page 33. Deguzman, M. The project Management Office - Gaining the Competitive Edge, ESI International, (1999), page 20.

Evaristo, K. D. Project Management Offices: A case of knowledge-based archetypes, Journal of Information Management, (2006), pages 420.

Frame, T. R. The Project Office. Crisp Publications, Inc. 1998.

Frame, T. R. The Project Office- A Key to Managing Projects Effectively. Crisp Publication, Inc. 1998.

Jr., W. G. "From the Editor," Project Management Journal, (1999), pages 4-5.

Kerzner, H. Project Management A System Aproach to Planning, Scheduling, and Controlling. Van Nosstrand Reinhold, 1992.

Kiani, S. Yousefi, V. Haji Yakhchali, S. Mellatdust, A. Identifying program critical success factors in construction industry, Management Science Letters 4 (2014) 1325-1334.

Knutson, J. Reengineering A Non-Centralized Project Structure into A Centralized Project Structure, PM NETWORK. (1995)

Koppelman, Q. W. Project Teams: The Role of the Project Office, (1998), page 33-36. 4 (8).

Levine, H. A. Teamocracy and Project Management : A Conundrum- A Case for the Project Office, PM NETWORK. (1996).

Noori, Sh., investigation of the role of project management office in success of project-based organizations and making some 
recommendationsfor implementation of project management office, M.Sc. thesis in construction and project management, Department of architecture, University of Tehran, (2009).

Pinto, J. K. Dissertation; Project Implementation:A Determination of Its Critical Success Factors,Moderators and Their Relative Importance Across the Project Life Cycle, University of Pittsburgh, 1986.

PMBOK. A Guide to the Project Management Body of Knowledge (PMBOK), 2013.

Terry Cooke-Davies, The real success factors on Projects, International Journal of Project Management, 202, 20(3), (2002), 185-190

Toor, S. Ogunlana, S., Critical COMs of Success in large-scale Construction Projects, International Journal of Project Management, (2008), 26, 420-430.

The standard for program management-third edition, PMI, 2013.

Vandersluis, C. Now Is A Good Time for A Project Office Comeback, (1998) page 25.

Ward, L. Project Management Terms, A Working Glossary, Second Edition, ESI International, 2000. 